\title{
Multimodal Optical Coherence Tomography in Visualization of Brain Tissue Structure at Glioblastoma (Experimental Study)
}

DOI: 10.17691/stm2016.8.1.10

Received February 9, 2015

K.S. Yashin, PhD Student, Department of Neurosurgery';

M.M. Karabut, Junior Researcher, Laboratory of the Study of Optical Structure of Biotissue, Institute of Biomedical Technologies;

V.V. Fedoseeva, Junior Researcher, Laboratory Neuromorphology3;

A.S. Khalansky, MD, PhD, Leading Researcher, Laboratory Neuromorphology3;

L.A. Matveev, PhD, Researcher, Laboratory of Optical Coherence Tomography, Institute of Biomedical Technologies²; Researcher, Department of Geophysical Studies4;

V.V. Elagin, Researcher, Laboratory of High Resolution Microscopy and Genetic Technologies, Institute of Biomedical Technologies;

S.S. Kuznetsov, MD, DSc, Professor, Department of Pathological Anatomy²;

E.B. Kiseleva, PhD, Junior Researcher, Laboratory for the Study of Optical Structure of Biotussie, Institute of Biomedical Technologies;

L.Ya. Kravets, MD, DSc, Professor, Chief Researcher, Group Microneurosurgery';

I.A. Medyanik, MD, PhD, Senior Researcher, Group Microneurosurgery';

N.D. Gladkova, MD, DSc, Professor, Vice Director for Science, Institute of Biomedical Technologies²

${ }^{1}$ Privolgzhsky Federal Medical Research Center, Ministry of Health of the Russian Federation,

18 Verkhne-Volzhskaya naberezhnaya St., Nizhny Novgorod, 603155, Russian Federation;

${ }^{2}$ Nizhny Novgorod State Medical Academy, 10/1 Minin and Pozharsky Square, Nizhny Novgorod, 603005,

Russian Federation;

${ }^{3}$ Research Institute of Human Morphology, Zurupy St., 3, Moscow, 117418, Russian Federation;

${ }^{4}$ Institute of Applied Physics, Russian Academy of Sciences, 46 Ul'yanova St., Nizhny Novgorod, 603950,

Russian Federation

The aim of the investigation was to evaluate the performance of multimodal OCT (MM OCT) for differential diagnostics of normal and diseased brain tissue using an experimental model of glioblastoma.

Materials and Methods. The spectral domain MM OCT device developed at the Institute of Applied Physics of the Russian Academy of Sciences (Nizhny Novgorod, Russia) was used for the study. It provides two modes of investigation: cross-polarization OCT (CP OCT) and microangiographic OCT (MA OCT). The instrument features the following characteristics: rate of information gathering - 20,000 A-scans per second; wavelength $-1.3 \mu \mathrm{m}$; shot size $-\sim 4 \times 2 \mathrm{~mm}$; lateral resolution $-20 \mu \mathrm{m}$; axial resolution $-10-15 \mu \mathrm{m}$. The 0CT investigation was performed on an experimental 101.8 rat brain glioblastoma tumor model inoculated and maintained in the Research Institute of Human Morphology. To evaluate the signal parameters typical of the tumor and of normal brain tissue, CP OCT and MA OCT images were compared with histological specimens (stained with hematoxylin and eosin). Analysis of the MA OCT images was performed on the basis of comparison with the findings of ZOOM-microscopy.

Results. The model of the rat 101.8 glioblastoma helped to identify links between CP OCT images of areas of brain tissue and their morphological structure. We performed a comparative evaluation of the signals from the glial tumor and from normal brain tissue. MA OCT allowed the visualization of the blood vessels both in the tumor and in the normal brain tissues, revealing changes in the form and sizes typical of the tumor vessels.

Conclusion. MM OCT is an innovative technology with potential for use in intraoperational diagnoses of glial tumors of the brain. The ability to combine several modes of investigation enables information to be obtained simultaneously about the structure of the tissues and about any peculiarities of the structure of the different elements of their microvascular network.

Key words: optical coherence tomography; microangiographic OCT; glioblastoma; cross-polarization OCT; multimodal OCT; experimental model of tumor; 101.8 rat glioblastoma; intraoperative diagnosis.

Brain surgery is accompanied by the risks of neurologic impairment, especially during manipulations in eloquent areas. Moreover, in the case of infiltrative neoplasms the surgeon faces difficulties in determining their boundaries and in observing a balance between radicality and what is physiologically permissible. Such issues justify the implementation of technological advances in neurosurgery to enable accurate surgical planning, both

For contacts: Konstantin S. Yashin, e-mail: jashinmed@gmail.com 
before skin incision by applying neuronavigation systems, and even during the surgery, by using different methods of intraoperative diagnostics for the determination of the boundaries and of tumor localization (fluorescent navigation, ultrasound scanning, videoangiography etc.), as these allow surgical intervention to be performed with maximum accuracy and minimum damage to the normal brain tissue [1]. However, none of these methods completely satisfies the requirements of neurosurgeons. This is particularly so during surgery on malignant gliomas, where 5-ALA-navigation gives both false positive and false negative results, because information about the boundaries of the tumor is mediated and realized through the peculiarities of its metabolism. This justifies the search for new methods for intraoperative determination of tumor boundaries, based on obtaining direct information about the structure of normal and pathologically changed brain tissue. Currently in this regard, optical diagnostic tools are considered the most promising, in particular, multimodal optical coherence tomography (MM OCT).

Optical coherence tomography is an emerging and promising technique for in vivo diagnostics in neurosurgery, which has great potential as a tool for determination of the state of neural tissues during surgical intervention. The MM OCT setup used in this work has been supplemented by polarization mode and dynamic microangiography in addition to the standard OCT mode (detection of backscattering, probing tissue radiation). Application of MM OCT in the clinical practice can potentially allow for obtaining a wide range of information about the state of the brain tissue during surgical intervention. To evaluate the MM OCT methods the experimental studies on animal tumor models are needed. This experiments also allow to develop an algorithm for evaluating the information obtained. Thus, this work was performed using rat glial tumors as a model, in conditions which were as close as possible to those of standard neurosurgical procedures.

The aim of the investigation was to evaluate the performance of multimodal OCT for differential diagnostics of normal and diseased brain tissue using an experimental model of glioblastoma.

Materials and Methods. The spectral domain MM OCT device (Figure 1) developed at the Institute of Applied Physics of the Russian Academy of Sciences (Russia) was used for the study. It provides two modes of investigation: cross-polarization OCT (CP OCT) and microangiographic OCT (MA OCT).

Characteristics of the device. Spectral OCT based on the principles described in [2-6]. The CP OCT mode has an active polarization control system that maintenance circular polarization as described in [7]. The obtained CP OCT image includes two images: top image in copolarization and bottom image in cross-polarization, which are obtained by separate registration of the scattered radiation in two channels respectively parallel and perpendicular to the polarization of the probing radiation. Original approach is applied to perform the en face visualization of microvascular network in MA OCT mode. This approach is based on utilization of the 3D dataset of complex-valued OCT signals as described in details in [8].

\section{Technical specifications of the MM OCT device}

Standard mode: registration an intensity image (copolarization):

central wavelength $-1,310 \mathrm{~nm}$;

A-scan rate $-20,000 \mathrm{~s}^{-1}$;

radiation power $-15 \mathrm{~mW}$;

lateral resolution $-20 \mu \mathrm{m}$;

axial resolution $-10-15 \mu \mathrm{m}$;

depth of scanning in free space $-2 \mathrm{~mm}$;

type of scanning - contactless;

maximum image size $-4 \times 2 \mathrm{~mm}$.

Supplementary modes:

cross-polarization (CP OCT) - real-time construction of image in cross-polarization mode $4 \times 2 \mathrm{~mm}$ in size;

3D CP OCT - real-time construction of 3D images in coand cross-polarization, each with dimensions $4 \times 4 \times 2 \mathrm{~mm}$ (planar dimensions $\times$ depth);

microangiographic OCT - acquiring of data for subsequent construction of en face projection of the microvasculature over an area of $2 \times 2 \mathrm{~mm}$ [8].

The physical principle of vascular network visualization (MA OCT) is based on the determination of the temporal variability in the full complex signal of each image element forming the speckle-pattern. The processing is based on the high-pass filtering of the temporal speckle evolution to isolate high-frequency speckle variations that indicate the presence of the liquids and flows. In the areas with moving scatterers the frequency of phase and amplitude variations of the complex signal of speckles
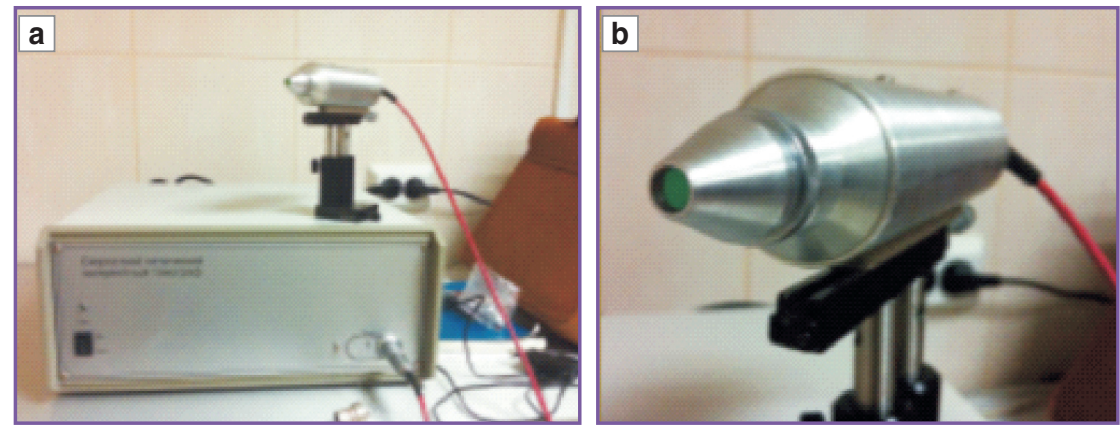

Figure 1. System of obtaining MM OCT images: (a) structure of multimodal OCT; (b) probe with an end window 
are higher than for the surrounding motionless tissue; this indicates the presence of flowing blood in these regions. While evaluation of the speckle variability should be performed for 3D volume the so-called M-Mode like scanning pattern was applied [8]. This ensures further space-time filtration of the consequently recorded and considerably overlapped A scans obtained during slow lateral scanning. To isolate the flows we selected an cutoff frequency of the high-pass filter of $96 \mathrm{~Hz}$. This cut-off frequency allows visualization of the regions with flowing blood (areas with stationary blood are not visualized).

Experimental tumor models. Taking into account the necessity of investigating MM OCT opportunities in the visualization and differential diagnosis of the normal nervous tissue and of the tumor, the selection of experimental model of malignant tumor was based on the following criteria: 1) the tumor must originate from the glial cells; 2) tumor growth and the resulting changes must be predictable and reproducible; 3) the properties the tumor must show characteristics typical of human, intracerebrally growing gliomas: neovascularization, breach of the blood-brain barrier, lack of a capsule, and invasive growth. Chemically induced glioma models meet these criteria [9, 10].

As an object of study we selected for a model the 101.8 rat glioblastoma, inoculated and maintained in the Scientific Research Institute of Human Morphology (Russia). The tumor was originally obtained in 1967 as a result of the injection of 7,12-dimethyl-(a)-benzanthracene into the right hemisphere of the cerebellum of a female Wistar rat. During serial intracerebral passage, starting from passage 14 a malignant tumor was formed that, according to its histobiology, was close in properties to an anaplastic astrocytoma. The tumor took on the homogeneous structure of a glioblastom and this has been stably preserved during following work with this model [9].

The work was performed on 5 female Wistar rats inoculated with rat glioblastoma 101.8. Transplantation of the tumor was performed in the Institute of Human Morphology using the following method: in the right parietal region lateral to the sagittal suture by $2 \mathrm{~mm}$ and posterior to the coronary seams by $2 \mathrm{~mm}$ we made a hole with a diameter of $2 \mathrm{~mm}$ with a dental bur. The dura mater was opened with an injection hypodermic needle and $10^{5}-10^{6}$ tumor cells were injected into the given area with a trocar.

The investigation was performed on day 7 after the rat 101.8 glioblastoma had been inoculated, when the tumors had reached $\sim 0.7 \mathrm{~cm}$ in size and spread to the cerebral cortex. The surgical procedure was performed according to the general regulations described in a number of works [11-14]. The CP OCT signal recording with the formation of co- and cross-polarization images was performed in vivo after craniotomy and ex vivo on the extracted brain after decapitation. To verify the structure of the nervous tissue represented in the CP OCT images, samples of the brain containing tumors were collected for parallel histological analysis. The samples were fixed in $10 \%$ formalin for $48 \mathrm{~h}$; several cross sections were taken in the central area, coinciding with the plane of the CP OCT images, and stained with hematoxylin and eosin. The cross sections were described by a morphologist and photographed in transmitted light with a Leica DM2500 DFC (Leica Microsystems, Germany) microscope, equipped with a digital camera.

The vasculature images were generated with MA OCT after processing of the signals obtained in vivo. The findings were compared with the corresponding images of the vascular network obtained with fluorescent stereomicroscopy on an Axio Zoom.V16 (Carl Zeiss, Germany).

On working with animals we were guided by the Regulations for work with experimental animals [15] and the International recommendations on medical-biological studies with animals [16]. All the experiments strictly complied with the ethical principles provided by the European Convention on the Protection of Vertebrate Animals used for Experimental and other scientific goals (accepted in Strasburg on March 18, 1986 and approved in Strasburg on June 15, 2006). The study is approved by the Ethical Committee of the Nizhny Novgorod State Medical Academy.

Results and Discussion. MM OCT study was performed for all the cortex of the affected hemisphere. Acquired CP OCT images are shown in Figures 2 and 3 and clearly visualize three areas which differed in the nature of their signals.

In the area of normal cortex (Figures 2 (a), (b) and 3 (a), (b); the area within the yellow dotted line) in the co-polarization CP OCT images there is a homogeneous signal up to the maximum penetration depth of the probing radiation. The normal in this area contains 6 layers of cells and fibers differentiated by their ordered location (Figure $3(\mathrm{~g})$ ). This well-orientated horizontalvertical distribution of the structural elements formed the homogeneous OCT signal.

In the peritumoral area (Figures 2 (a), (b) and 3 (a), (b); the area within the green dotted line) the OCT signal is less homogeneous, and the penetration depth of the probing radiation is reduced. Histotomographic comparison demonstrates a decrease in penetration depth of the probing radiation in the CP OCT image, corresponding to the contours of the peritumoral area on the histological preparation (Figure 3 (f) and 3 (a), (b); the area within the green dotted line). On the histological preparations (Figure 3 (c), (f)) there is an infiltration in the area of the cortex by groups of tumor cells with a local increase in cell density causing the formation of a heterogeneous (inhomogeneous) signal with areas of increased intensity in co-polarization.

In the area of tumor invasion - destruction of the cortex with the tumor node - the signal is sharply heterogeneous, but the penetration depth of probing radiation varies greatly along the transverse coordinate (Figures 2 (a), (b) and 3 (a), (b); the area within the blue dotted line). On the corresponding part of the histological preparation (Figure 3 (c)-(e)) disorganized tumor tissue is visible, and is characterized by areas of continuous 

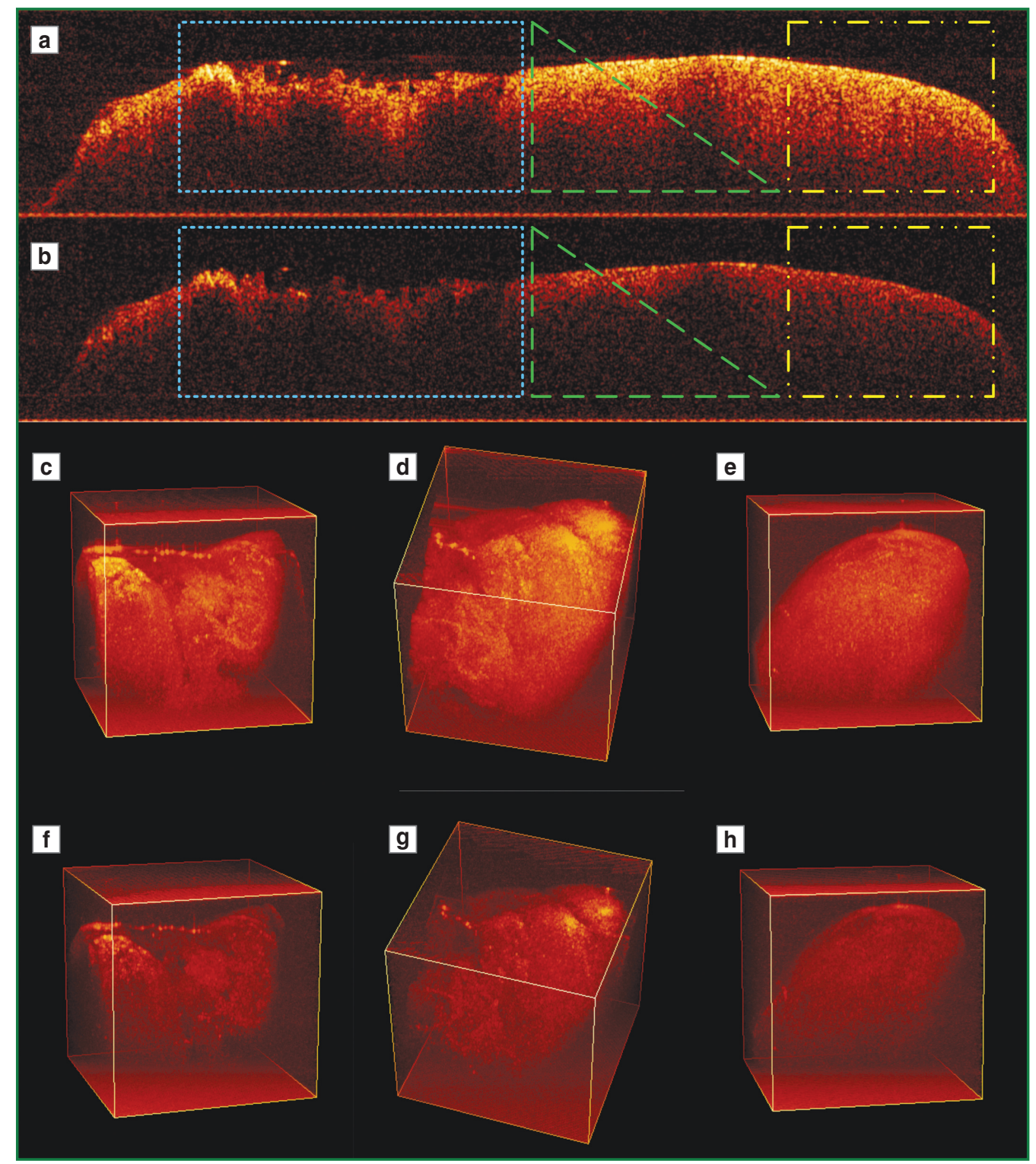

Figure 2. CP OCT visualization of rat brain with an inoculated glioma 101.8: (a) image in co-polarization; (b) image in crosspolarization: blue dotted line - area of destruction of the cortex with a tumor node; green dotted line - peritumoral area; yellow dotted line - area of the normal cortex; images (a) and (b) consist of several CP OCT images, the length of each being $13.5 \mathrm{~mm}$; (c)-(h) three dimensional (3D) reconstructions of the cortex areas in co- (c)-(e) and cross-polarization (f)-(h): (c), (f) area of destruction with a tumor node; (d), (g) peritumoral area; (e), (h) region of normal cortex

accumulation of tumor cells, mosaically located necrosis, and small hemorrhages. These foreign inclusions change the optical properties of the brain tissue and deform the homogenous signal typical of the structured cortex (Figures 2 (a), (b) and 3 (a), (b); within the yellow dotted line). The differences between the areas described are also distinctly visible in the 3D images in co-and crosspolarization (Figure 2 (c)-(h)).

Visually defined differences in the character of the CP OCT signal between the normal brain tissue and the tumor allow us to consider CP OCT as a potential method for intraoperative determination of the boundaries of infiltrative gliomas, as is required for achieving the most effective resection of the tumor, which is in its turn is significantly correlated to the progressive-free survival [17-23].

Initial attempts have been made by various research groups to determine accurate criteria for the differential diagnosis of tumor and normal brain tissue according to the OCT signal character of intensity images (for MM OCT, this corresponds to the image in the co-polarization). Thus, Bohringer et al., on the basis of qualitative analysis of OCT images, obtained over time, of glial tumors of different malignancy (42 biopsies) identified the degree of signal homogeneity as a differential criterion, wherein the tumor tissue and the peritumoral area (infiltration zone) differed in the heterogeneous character of their signals, from the 

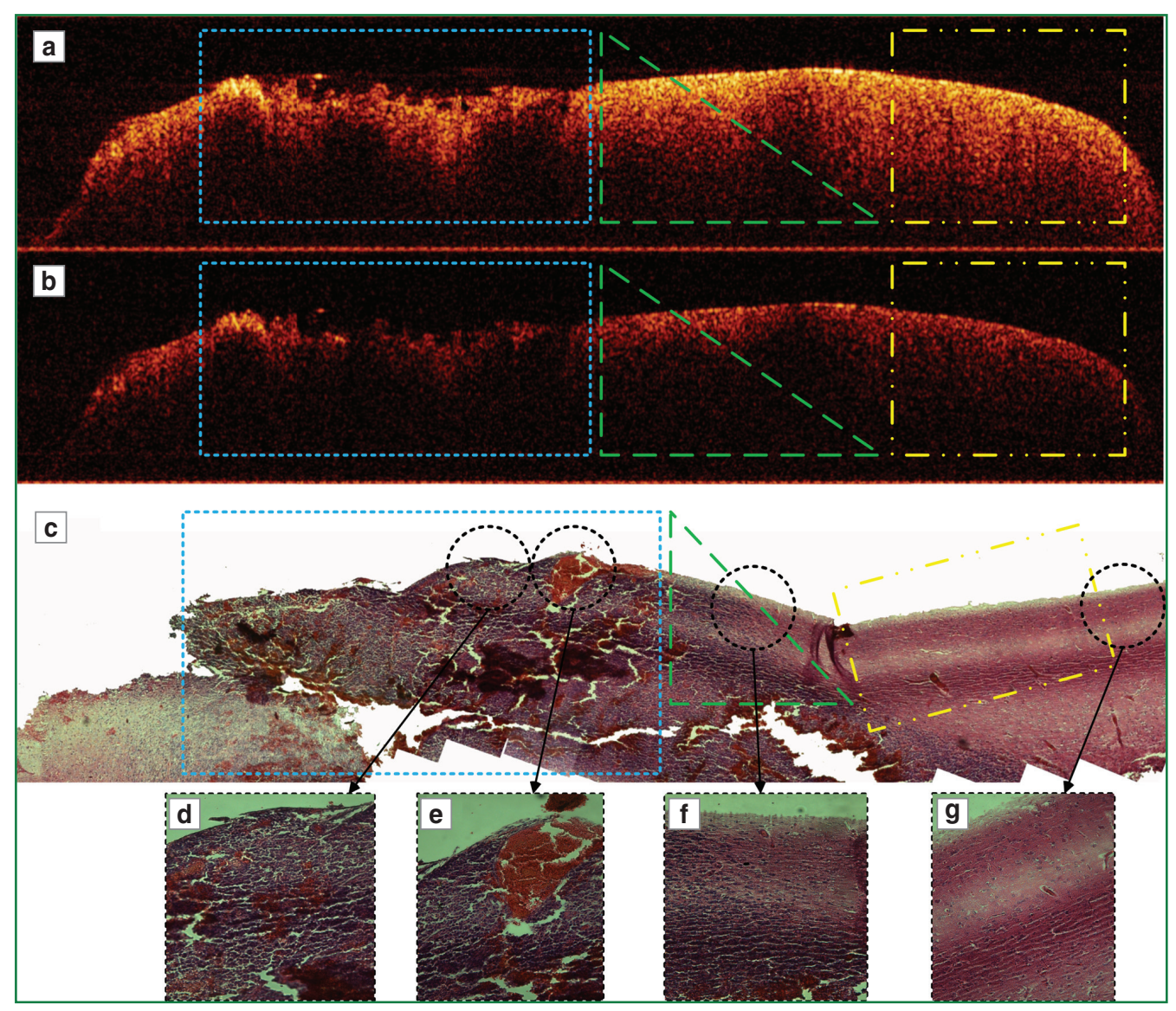

Figure 3. Histotomographic comparison of CP OCT image of rat brain with an area of destruction by glioblastoma 101.8 presented in Figure 2: (a) image in co-polarization; (b) image in cross-polarization; (c) histological preparation of the same area of the brain stained with hematoxylin and eosin, size $12.0 \times 3.0 \mathrm{~mm}$ : blue dotted line - area of tumor invasion (destruction of the cortex with a tumor node); green dotted line - peritumoral area; yellow dotted line - area of the normal cortex; (d)-(g) separate parts of the histological preparation, size $0.49 \times 0.65 \mathrm{~mm}$ : (d) tumor with areas of liquefactive necrosis; (e) area of hemorrhage in the tumor; (f) spreading of the tumor in the brain cortex in the form of single bundles of tumor cells; (g) region of normal cortex

homogeneous character of the normal brain tissue [24, 25]. A high degree of correlation between the character of the OCT signal and the histological findings was determined ( $\chi^{2}$ test; $\left.r=0.99\right)$ [25]. Kut et al. attempted a more objective quantitative evaluation of the signal with a determination of the coefficients of scattering as the differential criterion [26]. During the investigation the following coefficients of scattering were determined: for normal brain tissue $-6.2 \pm 0.8 \mathrm{~mm}^{-1}$; for high malignancy gliomas $-3.9 \pm 1.6 \mathrm{~mm}^{-1}$, in the infiltration zone $-7.1 \pm 1.0 \mathrm{~mm}^{-1}$; for low malignancy gliomas $4.0 \pm 1.4 \mathrm{~mm}^{-1}$, and in the infiltration zone $-2.7 \pm 1.0 \mathrm{~mm}^{-1}$. In the same work the diagnostic accuracy of OCT as a method for determination of the boundaries of the removed tumor was determined on the basis of the OCT findings from 16 patients. They showed high sensitivity $(92-100 \%)$ and specificity $(80-100 \%)$ according to the calculation of the coefficient of scattering. A number of scientists suggested this as the first technological solution for intraoperative OCT use in neurosurgery, for example, as a module of the microscopes used for microneurosurgery [27-29].
Our group have obtained the first OCT images of the glioma and the normal brain tissue in cross-polarization mode. The character of the signal in both cases generally corresponds to the signal in co-polarization (Figures 2 (a) and 3 (a)) and to the general morphological structure of the preparation (Figure 3 (c)).

Schmitt et al. found that the signal in the crossimage is the consequence of coherent cross-scattering and birefringence in the biotissue [30]. A number of works by Gladkova et al. have shown that the use of polarized radiation can increase informative value of the method, for example, with in vivo separation of pathophysiological processes (inflammation, fibrosis and neoplasia) connected with the changes in spatial and structural organization of the collagen fibers of the mucosae of internal organs [31-34]. In particular, it was found that the addition of the image in cross-polarization to the traditional OCT image considerably increased the effectiveness of the diagnosis of superficial bladder cancer [32]. The analysis of OCT images in crosspolarization demonstrated a sensitivity of $93.7 \%$ (against $81.2 \%$ on the analysis of OCT images in the 

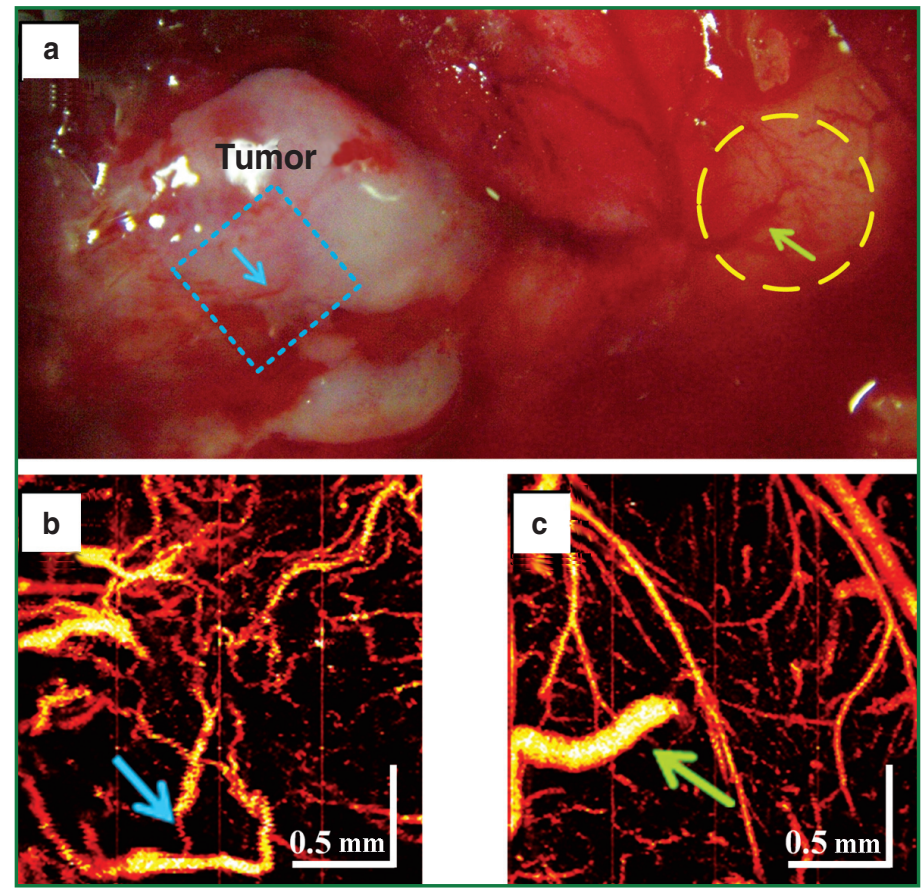

Figure 4. State of the microvasculature of rat glioblastoma 101.8 and the normal brain cortex near the tumor node according to the data from OCT microangiography: (a) image of microcirculation obtained with an Axio Zoom. V16 stereomicroscope; (b) OCT microangiogram of the area of normal brain cortex during the excision of the tumor node; (c) OCT microangiogram of rat glioblastoma 101.8. The arrows show the corresponding vessels. Images (b) and (c) were obtained from the two areas corresponding to the zones within the blue and yellow dotted lines in the CP OCT image represented in Figure 2 (a), (b) initial polarization, $p<0.0001)$, a greater specificity $84 \%$ (against $70.0 \%, p<0.001$ ) and accuracy - 85.3\% (against $71.5 \%, p<0.001$ ) in the determination of squamous malignant lesions of the bladder [32]. However the peculiarities and sources of formation of the cross-polarization signal from normal brain tissue and pathological brain tissue have not previously been studied.

The identified capacity of OCT to differentiate tumor tissue allows it to be considered as a potential method of optical express-biopsy for the stereotactic biopsy of deep brain neoplasms and for intraoperative determination of the boundaries of infiltrative brain tumors.

The second mode of the device - spectral MA OCT - allows the visualization of changes in the form and size of brain vessels in the norm and under pathological conditions. The results obtained with MA OCT are shown in Figure 4. It is visible that the tumor vessels of the rat 101.8 glioblastoma (Figure 4 (b)) have a different shape (Figure 4 (c)) compared to the normal brain vessels: they are convoluted, with uneven contours to the lumen (Figure 4 (b)).

There a reason to believe that the high spatial resolution of OCT and the possibility of quantitative evaluation of the microvasculature allow unique information to be obtained about cerebral hemodynamics and metabolism and the corresponding activity of the brain and its dysfunction [35-40]. For instance, the OCT method has shown the effect of cocaine on cerebral blood flow, which manifests itself in marked vasospasm and ischemia foci [41]. Our results of using MA OCT enable us to propose the possibilities for its clinical use. We consider that in the long-term the potential for periodic monitoring of the state of the microvasculature of the brain cortex during neurosurgical interventions could help prevent ischemic complications and, respectively, the occurrence of neurological deficiency in the postoperative period.

Thus, in the example of the rat 101.8 glioblastoma model it has been found that the character of CP OCT images of brain tissue areas reflect their different morphological structure. MA OCT allows the reliable visualization of tumor and normal brain vessels, differentiating the typical signs of tumor vessels (convolution, uneven contours etc.).

Conclusion. Multimodal OCT including crosspolarization and microangiographic OCT modes is a promising method of intraoperative diagnosis of gliomas. The possibility to combine several investigation modes allows to simultaneously receive information on both the tissue structure and the state of the microvasculature. Such an OCT technique has great potential as a method for determination of the boundaries of infiltrative gliomas, based on an evaluation of the structure of the tissue and the specific details of different aspects of the microvascular network.

Acknowledgements. The authors express their deep gratitude to the Director of the Scientific Research Institute of Human Morphology, Olga V. Makarova for her help in the organization of the study, and in the choice of the optimal experimental model of tumor to investigate the possibilities of multimodal OCT for diagnostics on the state of nervous tissue in the case of glial tumors.

Study Funding. The study was performed with the financial support of a grant from the Government of the Russian Federation, the Ministry of Education and Science of the Russian Federation, contract No.14. B25.31.0015 (KMM, MLA, EVV, KSS, EBK, NDG) and grants from the Russian Foundation for Basic Research 
No.16-34-00995 mol_a (KMM, MLA, EVV) and No.1542-02513 r_povolzh'e_a (MLA).

Conflicts of Interest. The authors have no conflicts of interest.

\section{References}

1. Witiw C.D., Nathan V., Bernstein M. Economics, innovation, and quality improvement in neurosurgery. Neurosurg Clin N Am 2015; 26(2): 197-205, http://dx.doi.org/10.1016/ j.nec.2014.11.003.

2. Moiseev A.A., Gelikonov G.V., Terpelov D.A., Shilyagin P.A., Gelikonov V.M. Improvement of lateral resolution of spectral domain optical coherence tomography images in outof-focus regions with holographic data processing techniques. Quantum Electronics 2014; 44(8): 732-739, http://dx.doi. org/10.1070/QE2014v044n08ABEH015492.

3. Gelikonov V.M., Gelikonov G.V., Shilyagin P.A. Linearwavenumber spectrometer for high-speed spectral-domain optical coherence tomography. Optics and Spectroscopy 2009; 106(3): 459-465, http://dx.doi.org/10.1134/ s0030400x09030242.

4. Gelikonov V.M., Gelikonov G.V., Kasatkina I.V., Terpelov D.A., Shilyagin P.A. Coherent noise compensation in spectral-domain optical coherence tomography. Optics and Spectroscopy 2009; 106(6): 895-900, http://dx.doi.org/10.1134/ s0030400x09060174.

5. Gelikonov V.M., Gelikonov G.V., Terpelov D.A., Shabanov D.V., Shilyagin P.A. Suppression of image autocorrelation artefacts in spectral domain optical coherence tomography and multiwave digital holography. Quantum Electronics 2012; 42(5): 390-393, http://dx.doi.org/10.1070/ QE2012v042n05ABEH014852.

6. Shilyagin P.A., Gelikonov G.V., Gelikonov V.M., Moiseev A.A., Terpelov D.A. Achromatic registration of quadrature components of the optical spectrum in spectral domain optical coherence tomography. Quantum Electronics 2014; 44(7): 664-669, http://dx.doi.org/10.1070/ QE2014v044n07ABEH015465.

7. Gelikonov V.M., Gelikonov G.V. New approach to crosspolarized optical coherence tomography based on orthogonal arbitrarily polarized modes. Laser Physics Letters 2006; 3(9): 445-451, http://dx.doi.org/10.1002/lapl.200610030.

8. Matveev L.A., Zaitsev V.Y., Gelikonov G.V., Matveyev A.L., Moiseev A.A., Ksenofontov S.Y., Gelikonov V.M., Sirotkina M.A., Gladkova N.D., Demidov V., Vitkin A. Hybrid M-mode-like OCT imaging of three-dimensional microvasculature in vivo using reference-free processing of complex valued B-scans. Optics Letters 2015; 40(7): 14721475, http://dx.doi.org/10.1364/ol.40.001472.

9. Khalansky A.S., Kondakova L.I. Transplanted rat glioma 101.8.I. Biological characteristics. Klinicheskaya $i$ eksperimental'naya morfologiya 2013; 4(8): 63-68.

10. Barth R.F., Kaur B. Rat brain tumor models in experimental neuro-oncology: the C6, 9L, T9, RG2, F98, BT4C, RT-2 and CNS-1 gliomas. J Neurooncol 2009; 94(3): 299-312, http://dx.doi.org/10.1007/s11060-009-9875-7.

11. Goldey G.J., Roumis D.K., Glickfeld L.L., Kerlin A.M., Reid R.C., Bonin V., Schafer D.P., Andermann M.L. Removable cranial windows for long-term imaging in awake mice. Nat Protoc 2014; 9(11): 2515-2538, http://dx.doi.org/10.1038/ nprot.2014.165.
12. Mostany R., Portera-Cailliau C. A craniotomy surgery procedure for chronic brain imaging. J Vis Exp 2008; 12, http:// dx.doi.org/10.3791/680.

13. Park K., You J., Du C., Pan Y. Cranial window implantation on mouse cortex to study microvascular change induced by cocaine. Quant Imaging Med Surg 2015; 5(1): 97107, http://dx.doi.org/10.3978/j.issn.2223-4292.2014.11.31.

14. Keiner D., Heimann A., Kronfeld A., Sommer C., MuellerForell W., Kempski O., Oertel J. Towards a glioma model for surgical technique evaluation in the rat. $\mathrm{Br} J$ Neurosurg 2014; 28(1): 86-92, http://dx.doi.org/10.3109/02688697.2013. 804489.

15. Prikaz Minzdravsotsrazvitiya RF ot 23.08.2010 No.708n "Ob utverzhdenii Pravil laboratornoy praktik" [Ministry of Health and Social Development of the Russian Federation Decree No.708n as of Aug 23, 2010 "On Good Laboratory Practices"].

16. Mezhdunarodnye rekomendatsii (eticheskiy kodeks) po provedeniyu mediko-biologicheskikh issledovaniy $s$ ispol'zovaniem zhivotnykh [International guiding principles (ethical code) for biomedical research involving animals]. 1985.

17. Sanai N., Berger M.S. Glioma extent of resection and its impact on patient outcome. Neurosurgery 2008; 62(4): 753-766, http://dx.doi.org/10.1227/01.neu.0000318159.21731.cf.

18. Sanai N., Polley M.Y., McDermott M.W., Parsa A.T., Berger M.S. An extent of resection threshold for newly diagnosed glioblastomas. J Neurosurg 2011; 115(1): 3-8, http://dx.doi.org/ 10.3171/2011.2.jns10998.

19. Anokhina Yu.E., Gaidar B.V., Martynov B.V., Svistov D.V., Papayan G.V., Grigorievsky D.I. Prognostic significance of surgery volume under fluorescent intraoperative diagnostic applications in patients with malignant brain gliomas. Vestnik rossiyskoy voenno-meditsinskoy akademii 2014; 1: 19-24.

20. Stummer W., Reulen H.J., Meinel T., Pichlmeier U., Schumacher W., Tonn J.C., Rohde V., Oppel F., Turowski B., Woiciechowsky C., Franz K., Pietsch T. Extent of resection and survival in glioblastoma multiforme: identification of and adjustment for bias. Neurosurgery 2008; 62(3): 564-576, http:// dx.doi.org/10.1227/01.neu.0000317304.31579.17.

21. McGirt M.J., Chaichana K.L., Gathinji M., Attenello F.J., Than K., Olivi A., Weingart J.D., Brem H., Quiñones-Hinojosa A.R. Independent association of extent of resection with survival in patients with malignant brain astrocytoma. J Neurosurg 2009; 110(1): 156-162, http://dx.doi.org/10.3171/2008.4.17536.

22. Kuhnt D., Becker A., Ganslandt O., Bauer M., Buchfelder M., Nimsky C. Correlation of the extent of tumor volume resection and patient survival in surgery of glioblastoma multiforme with high-field intraoperative MRI guidance. Neuro Oncol 2011; 13(12): 1339-1348, http://dx.doi.org/10.1093/ neuonc/nor133.

23. Sanai N., Polley M.Y., McDermott M.W., Parsa A.T., Berger M.S. An extent of resection threshold for newly diagnosed glioblastomas. J Neurosurg 2011; 115(1): 3-8, http://dx.doi.org/ 10.3171/2011.2.JNS10998.

24. Böhringer H.J., Boller D., Leppert J., Knopp U., Lankenau E., Reusche E., Hüttmann G., Giese A. Time-domain and spectral-domain optical coherence tomography in the analysis of brain tumor tissue. Lasers Surg Med 2006; 38(6): 588-597, http://dx.doi.org/10.1002/lsm.20353.

25. Böhringer H.J., Lankenau E., Stellmacher F., Reusche E., Hüttmann G., Giese A. Imaging of human brain tumor tissue by near-infrared laser coherence tomography. Acta Neurochir (Wien) 2009; 151(5): 507-517, http://dx.doi.org/10.1007/ s00701-009-0248-y. 
26. Kut C., Chaichana K.L., Xi J., Raza S.M., Ye X., McVeigh E.R., Rodriguez F.J., Quiñones-Hinojosa A., Li X. Detection of human brain cancer infiltration ex vivo and in vivo using quantitative optical coherence tomography. Sci Transl Med 2015; 7(292): 292ra100, http://dx.doi.org/10.1126/ scitransImed.3010611.

27. Kantelhardt S.R., Finke M., Schweikard A., Giese A. Evaluation of a completely robotized neurosurgical operating microscope. Neurosurgery 2013; 72(Suppl 1): A19-A26, http:// dx.doi.org/10.1227/NEU.0b013e31827235f8.

28. Finke M., Kantelhardt S., Schlaefer A., Bruder R., Lankenau E., Giese A., Schweikard A. Automatic scanning of large tissue areas in neurosurgery using optical coherence tomography. Int J Med Robot 2012; 8(3): 327-336, http://dx.doi. org/10.1002/rcs.1425.

29. Lankenau E., Klinger D., Winter C., Malik A., Müller H., Oelckers S., Pau H.-W., Just T., Hüttmann G. Combining optical coherence tomography (OCT) with an operating microscope. In: Advances in medical engineering. Springer Berlin Heidelberg; 2007 , p. 343-348, http://dx.doi.org/10.1007/978-3-54068764-1_57.

30. Schmitt J.M., Xiang S.H. Cross-polarized backscatter in optical coherence tomography of biological tissue. Opt Lett 1998; 23(13): 1060-1062, http://dx.doi.org/10.1364/ol.23. 001060.

31. Gladkova N., Kiseleva E., Streltsova O., Prodanets N., Snopova L., Karabut M., Gubarkova E., Zagaynova E. Combined use of fluorescence cystoscopy and crosspolarization OCT for diagnosis of bladder cancer and correlation with immunohistochemical markers. J Biophotonics 2013; 6(9): 687-698, http://dx.doi.org/10.1002/jbio.201200105.

32. Gladkova N., Streltsova O., Zagaynova E., Kiseleva E., Gelikonov V., Gelikonov G., Karabut M., Yunusova K., Evdokimova O. Cross-polarization optical coherence tomography for early bladder-cancer detection: statistical study. J Biophotonics 2011; 4(7-8): 519-532, http://dx.doi.org/10.1002/jbio.201000088.

33. Gladkova N., Kiseleva E., Robakidze N., Balalaeva I., Karabut M., Gubarkova E., Feldchtein F. Evaluation of oral mucosa collagen condition with cross-polarization optical coherence tomography. J Biophotonics 2013; 6(4): 321-329, http://dx.doi.org/10.1002/jbio.201200059.
34. Kiseleva E., Kirillin M., Feldchtein F., Vitkin A., Sergeeva E., Zagaynova E., Streltzova O., Shakhov B., Gubarkova E., Gladkova N. Differential diagnosis of human bladder mucosa pathologies in vivo with cross-polarization optical coherence tomography. Biomed Opt Express 2015; 6(4): 1464-1476, http://dx.doi.org/10.1364/boe.6.001464.

35. Leitgeb R.A., Werkmeister R.M., Blatter C., Schmetterer L. Doppler optical coherence tomography. Prog Retin Eye Res 2014; 41: 26-43, http://dx.doi.org/10.1016/j. preteyeres.2014.03.004.

36. Chong S.P., Merkle C.W., Leahy C., Srinivasan V.J. Cerebral metabolic rate of oxygen (CMRO2) assessed by combined Doppler and spectroscopic OCT. Biomed Opt Express 2015; 6(10): 3941-3951, http://dx.doi.org/10.1364/ BOE.6.003941.

37. Devor A., Sakadzic S., Srinivasan V.J., Yaseen M.A., Nizar K., Saisan P.A., Tian P., Dale A.M., Vinogradov S.A., Franceschini M.A., Boas D.A. Frontiers in optical imaging of cerebral blood flow and metabolism. J Cereb Blood Flow Metab 2012; 32(7): 1259-1276, http://dx.doi.org/10.1038/ jcbfm.2011.195.

38. Srinivasan V.J., Sakadžić S., Gorczynska I., Ruvinskaya S., Wu W., Fujimoto J.G., Boas D.A. Quantitative cerebral blood flow with optical coherence tomography. Opt Express 2010; 18(3): 2477-2494, http://dx.doi.org/10.1364/ OE.18.002477.

39. Lee J., Wu W., Lesage F., Boas D.A. Multiple-capillary measurement of RBC speed, flux, and density with optical coherence tomography. J Cereb Blood Flow Metab 2013; 33(11): 1707-1710, http://dx.doi.org/10.1038/jcbfm.2013.158.

40. Srinivasan V.J., Atochin D.N., Radhakrishnan H., Jiang J.Y., Ruvinskaya S., Wu W., Barry S., Cable A.E., Ayata C., Huang P.L., Boas D.A. Optical coherence tomography for the quantitative study of cerebrovascular physiology. J Cereb Blood Flow Metab 2011; 31(6): 1339-1345, http://dx.doi.org/10.1038/ jcbfm.2011.19.

41. Ren H., Du C., Yuan Z., Park K., Volkow N.D., Pan Y. Cocaine-induced cortical microischemia in the rodent brain: clinical implications. Mol Psychiatry 2012; 17(10): 1017-1025, http://dx.doi.org/10.1038/mp.2011.160. 